\title{
Oxidative of Some Substituted Benzaldehydes by Isoqauinolinium Bromochromate
}

\author{
Arun Kumar Dwivedi ${ }^{1 *}$, Arvind Prasad Dwivedi ${ }^{2}$, K. N. Sharma ${ }^{3}$ \\ ${ }^{I}$ Department of Chemistry, A.P.S. University, Rewa-486003 (M.P.) India \\ ${ }^{2}$ Department of Chemistry, Govt. S.G.S.Govt.Auto.P.G.College Sidhi M.P.India \\ ${ }^{3}$ Department of Chemistry, Govt. Girls P.G. College Rewa-486001 (M.P.) India
}

*Corresponding Author: Arun Kumar Dwivedi, Department of Chemistry, A.P.S. University, Rewa486003 (M.P.) India.

\begin{abstract}
Oxidation of p-chlorobenzaldehyde and p-methyl benzaldehyde by Isoquinolinium bromochromate has been examined in acetic acid medium. The proposed intermediate involves in complex formation between $\mathrm{H}_{2} \mathrm{CrO}_{4}$ species of oxidant and keto form of substrate. The rate of reaction is enhanced by an increase in $[\mathrm{H}+]$, catalyst $\mathrm{Cu}++$ ion, and increase in percentage of acetic acid $(v / v)$. The effect of relative permittivity neutral salt, ionic strength and temperature was also carried out in support of the mechanism proposed. The derived rate law was verified graphically. We observed the oxidation with stoichiometric amounts (1:1) oxidant and substrate in the range of temperature $35^{\circ}$ and $40^{\circ} \mathrm{C}$.
\end{abstract}

Keywords: Oxidation, Intermediate, P-chlorobenzaldehyde, P-methylbenzaldehyde, stoichiometry.

\section{INTRODUCTION}

A halochromate of isoquinoline generic called Isoquinolinium bromochromate (IQBC) reagent is widely used in organic synthesis and in the chemistry of natural products. It is stable, low cost, less expensive and commercially available isoquinoline which has rarely been used in oxidation reactions. Recently IQBC has found wides spread applications as an useful oxidant in various chemical reactions such as the oxidation of alcohols ${ }^{1,2}$ ketones, ${ }^{3}$ and phenols ${ }^{4}$ etc. Never the less, the development of newer methods is currently gaining much attention due to importance of oxidation of para-substituted-chloro and methyl benzaldehydes by different oxidants such as selenium dioxide ${ }^{5}, \mathrm{~N}$ chlorosaccharin, ${ }^{6} \mathrm{~N}$-bromosaccharin ${ }^{7}$ and acid bromate ${ }^{8}$ etc. In substituted benzaldehydes keto-enol dynamic equilibrium is known to occur which leads different mechanism paths by the attack of reacting species of oxidant.

As our knowledge, there are no reports on application of IQBC in the oxidation of above compounds until now and also we have examined the reactivity in the oxidation of above compounds. Here in this research the, oxidation of P-substituted benzaldehydes with stoichiometric amounts of IQBC under conditions in the range of temperature 308 and $313 \mathrm{~K}$ can be carried out.

\section{EXPERIMENTAL}

All the chemicals used were of reagent grade and the solutions were prepared in double distilled water. The P-chlorobenzaldehyde and P-methyl benzaldehyde were of standard grade, their solutions was prepared in $\mathrm{CH}_{3} \mathrm{COOH}$ (B.D.H.). The IQBC was prepared by dissolving weighed quantity of chromium trioxide followed by addition of hydrobromic acid and isoquinoline for a specified time period. The AR grade $\mathrm{H}_{2} \mathrm{SO}_{4}$ and $\mathrm{Na}_{2} \mathrm{~S}_{2} \mathrm{O}_{3}$ (B.D.H.) were used as received after standardization properly. The stock solutions of all the reactants were prepared in double distilled water and standardized by different methods wherever necessary.

The purity determination of substrates and oxidant monitoring were accompanied by spectral methods.

The reaction was initiated by mixing previously thermostated solutions of the reactants at desire temperature and stirred magnetically. The reaction was followed by determing the unconsumed 
oxidant iodometrically. ${ }^{9}$ The pseudo first-order rate constants were determined from the linear plots of $\log$ (oxidant) against time graphs and the values were reproducible upto $\pm 4 \%$.

In the observed oxidation, the stoichiometric ${ }^{\mathbf{1 0 , 1 1}}$ amounts of IQBC oxidant under experimental conditions determined was found to be one mole of oxidant, per mole of each $\mathrm{p}-\mathrm{Cl}$ benzaldehyde and $\mathrm{p}-\mathrm{CH}_{3}$ benzaldehyde (1:1). The products, according to the stoichiometry were the corresponding $\mathrm{p}$ chloro benzoic acid and p-methyl benzoic acid obtained in excellent yields.

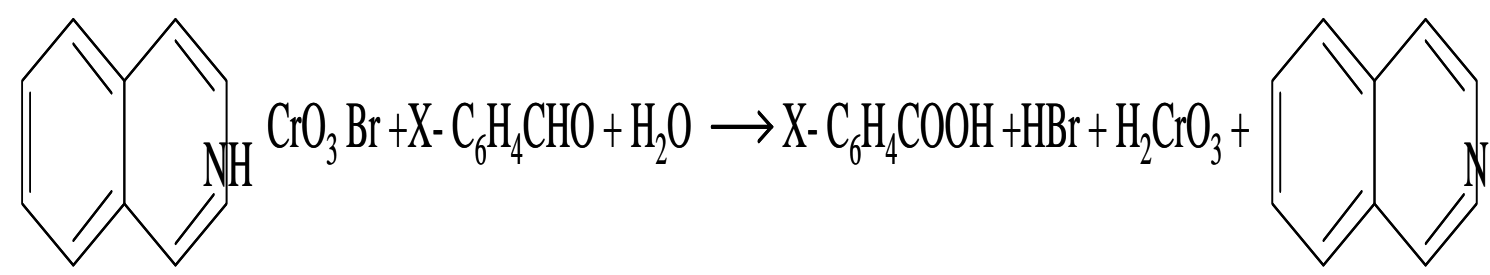

Where, $\mathrm{X}=-\mathrm{Cl}$ and $-\mathrm{CH}_{3}$ for para-chloro benzaldehyde and para-methyl benzaldehyde respectively.

The products were analyzed and the distillate was treated with 2,4-dinitrophenyl hydrazine (DNP). The DNP derivative products was precipitated and confirmed by determing their melting points, and other methods too.

\section{RESULTS AND DISCUSSION}

The concentration of oxidant IQBC was varied from $1.25 \times 10^{-3}$ to $5.00 \times 10^{-3}\left(\mathrm{~mol} \mathrm{dm}^{-3}\right)$ by keeping all other concentrations constant at fixed ionic strength and temperature. The pseudo first-order rate constants $\mathrm{k}_{\mathrm{obs}}$ were found to be constant indicating first-order dependence of the reaction with [oxidant]. One to zero order rate constants were found at higher concentration of substrates varied between $1.25 \times 10^{-2}$ to $6.66 \times 10^{-2}\left(\mathrm{~mol} \mathrm{dm} \mathrm{dm}^{-3}\right)$ at constant concentrations of all participants, and temperature (Table1). The plot of $\mathrm{k}^{-1}$ obs against [substrate] ${ }^{-1}$ (Fig.1) with positive intercept on Y-axis pours evidence of complex kinetics between reacting species $\mathrm{H}_{2} \mathrm{SO}_{4}$ and keto form of substrate. The pseudo first-order rate constant were found to increase as the $\left[\mathrm{H}^{+}\right]$increases from $1.00 \times 10^{-3}$ to $5.00 \times 10^{-3}\left(\mathrm{~mol} \mathrm{dm}^{-3}\right)$ keeping all other concentrations of reagents constant. The rate constant $(\mathrm{k})$ was calculated from the slope of $\log \left[\mathrm{H}^{+}\right]$against $\log \mathrm{k}_{\mathrm{obs}}$ plots and catalysed nature of $\mathrm{H}^{+}$was ascertained to reactions. Same reaction trend was observed by adding varied $\left[\mathrm{Cu}^{++}\right]$ions with that of relative permittivity. The addition of $\mathrm{NaCl}$ of different concentration to reaction mixture does not bring any more substantial change in reaction velocity. The velocity constants of the reaction were found to increase moderately with increase in solvent polarity (Table 2). The plot of $\log \mathrm{k}_{\mathrm{obs}}$ against $1 / \mathrm{D}$ was found to be linear with positive slope (Fig.2). The activation parameters determined from the effect of temperature are given in Table 3.

Table1. Effect of concentration of Substrate on reaction rate

$10^{3} \times[\mathrm{IQBC}]\left(\mathrm{mol} \mathrm{dm}^{-3}\right)=2.50(1,2)$;

$10^{3} \times\left[\mathrm{H}^{+}\right]\left(\mathrm{mol} \mathrm{dm}{ }^{-3}\right)=2.50(1), 1.50(2) ;$

$\mathrm{CH}_{3} \mathrm{COOH}-\mathrm{H}_{2} \mathrm{O}, \%(\mathrm{v} / \mathrm{v})=40(1), 30(2)$;

Temp. $\mathrm{k}=313(1), 308(2)$

\begin{tabular}{|c|c|c|c|}
\hline \multirow{2}{*}{$\begin{array}{l}\text { S. } \\
\text { No. }\end{array}$} & \multirow{2}{*}{$\begin{array}{c}{[\text { Substrate }] \times 10^{2}(\mathrm{~mol}} \\
\left.\mathrm{dm}^{-3}\right)\end{array}$} & \multicolumn{2}{|c|}{$10^{4} k_{\text {obs }}\left(\mathrm{s}^{-1}\right)$} \\
\hline & & $\begin{array}{c}\text { p-ClC }{ }_{6} \mathrm{H}_{4} \mathrm{CHO} \\
\text { p-chlorobenzaldeehyde } \\
(1)\end{array}$ & $\begin{array}{c}\text { p-CH } \mathrm{CH}_{3} \mathrm{C}_{6} \mathrm{H}_{4} \mathrm{CHO} \\
\text { p-methylbenzaldehyde } \\
(2)\end{array}$ \\
\hline 4. & 1.25 & - & 1.31 \\
\hline 5. & 1.50 & 0.94 & - \\
\hline 6. & 2.00 & 1.23 & 1.80 \\
\hline 7. & 2.50 & 1.35 & 2.12 \\
\hline 8. & 3.33 & - & 2.53 \\
\hline 9. & 4.00 & 2.04 & 2.74 \\
\hline 10. & 5.00 & 2.21 & 3.16 \\
\hline 11. & 6.66 & 2.28 & 3.23 \\
\hline
\end{tabular}




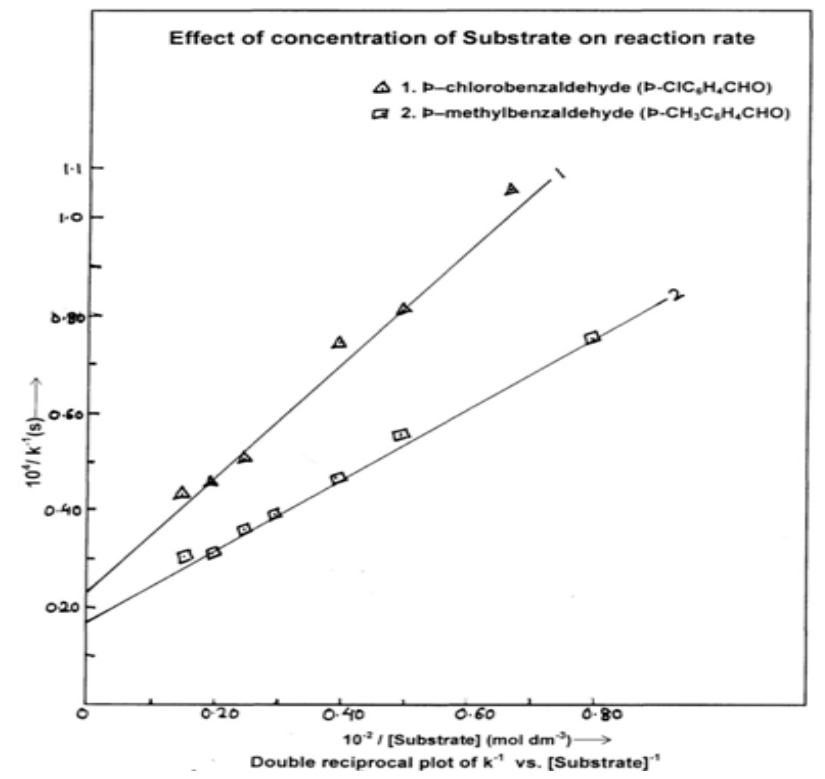

Figure1. $10^{3} \times[\operatorname{IQBC}]\left(\mathrm{mol} \mathrm{dm}^{-3}\right)=2.50(1,2) ; 10^{3} \times\left[\mathrm{H}^{+}\right]\left(\mathrm{mol} \mathrm{dm}^{-3}\right)=2.50(1), 1.50(2) ; \mathrm{CH}_{3} \mathrm{COOH}_{-} \mathrm{H}_{2} \mathrm{O} \%(\mathrm{~V} / \mathrm{V})$ =40 (1), 30 (2);Temp. $K=313$ (1), 308(2).

Table2. Effect of Solvent polarity on reaction rate

$10^{3} \times[\mathrm{IQBC}]\left(\mathrm{mol} \mathrm{dm}^{-3}\right)=2.50(1,2) ;$

$10^{2} \times[$ Substrate $]\left(\mathrm{mol} \mathrm{dm}^{-3}\right)=4.0(1), 2.0(2)$;

$10^{3} \times\left[\mathrm{H}^{+}\right]\left(\mathrm{mol} \mathrm{dm}^{-3}\right)=2.50(1), 1.50(2) ;$

$\mathrm{CH}_{3} \mathrm{COOH}-\mathrm{H}_{2} \mathrm{O}, \%(\mathrm{v} / \mathrm{v})=40(1), 30(2)$;

Temp. $\mathrm{k}=313(1), 308(2)$

\begin{tabular}{|c|c|c|c|c|}
\hline \multirow{2}{*}{$\begin{array}{l}\text { S. } \\
\text { No. }\end{array}$} & \multirow{2}{*}{$\begin{array}{c}\mathrm{CH}_{3} \mathrm{COOH}-\mathrm{H}_{2} \mathrm{O} \\
\%(\mathrm{v} / \mathrm{v})\end{array}$} & \multirow[t]{2}{*}{$10^{3} / \mathrm{D}$} & \multicolumn{2}{|c|}{$10^{4} \mathrm{k}\left(\mathrm{s}^{-1}\right) \longrightarrow$} \\
\hline & & & $\begin{array}{c}\text { p-ClC } \mathrm{CH}_{4} \mathrm{CHO} \\
\text { p-chlorobenzaldehyde } \\
(1)\end{array}$ & $\begin{array}{c}\text { p- } \mathrm{CH}_{3} \mathrm{C}_{6} \mathrm{H}_{4} \mathrm{CHO} \\
\text { p-methylbenzaldehyde } \\
(2)\end{array}$ \\
\hline 1. & 20 & 17.17 & 2.61 & 1.55 \\
\hline 2. & 30 & 19.15 & 1.73 & 1.78 \\
\hline 3. & 40 & 21.98 & 2.04 & 2.17 \\
\hline 4. & 50 & 25.64 & 2.32 & 2.63 \\
\hline 5. & 60 & 30.36 & 2.57 & - \\
\hline
\end{tabular}

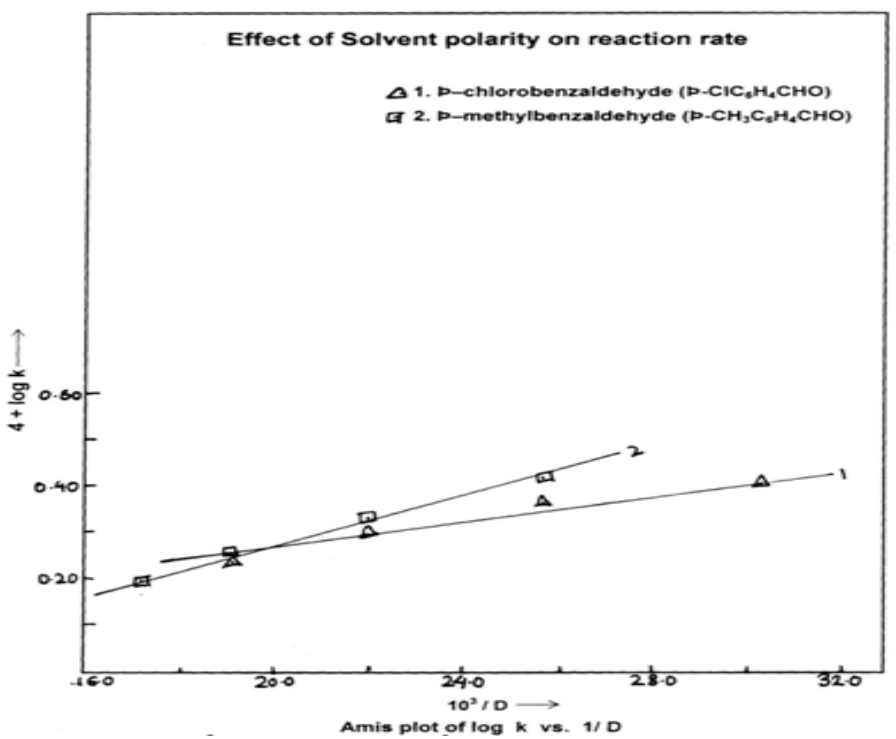

Figure2. $10^{2} \times[$ Substrate $]\left(\mathrm{mol} \mathrm{dm}^{-3}\right)=4.0(1), 2.0(2) ; 10^{3} \times[\operatorname{IQBC}]\left(\mathrm{mol} \mathrm{dm}^{-3}\right)=2.50(1,2) ; 10^{3} \times\left[\mathrm{H}_{2} \mathrm{SO}_{4}\right]\left(\mathrm{mol} \mathrm{dm}^{-}\right.$ $\left.{ }^{3}\right)=2.50(1), 1.50(2)$; Temp. $K=313$ (1), 308(2). 
Table3. Thermodynamic and activation parameters for some substituted benzaldehydes- Isoquinolinium bromochromate reactions

\begin{tabular}{|c|c|c|c|c|c|c|}
\hline $\begin{array}{l}\text { S. } \\
\text { No. }\end{array}$ & Substrate & $\begin{array}{c}\text { Ea } \\
\mathbf{k J}\left(\mathrm{mol}^{-1}\right)\end{array}$ & $\begin{array}{l}A \times \\
\left(\mathbf{s}^{-1}\right)\end{array}$ & $\begin{array}{c}\Delta \mathbf{H}^{\#} \\
\mathbf{k J}\left(\mathrm{mol}^{-1}\right)\end{array}$ & $\begin{array}{c}\Delta \mathbf{G}^{\#} \\
\mathbf{k J}\left(\mathrm{mol}^{-1}\right)\end{array}$ & $\begin{array}{c}-\Delta \mathbf{S}^{\#} \\
\mathbf{J K}^{-1}\left(\mathrm{~mol}^{-1}\right)\end{array}$ \\
\hline 1. & $\begin{array}{c}\mathrm{p}-\mathrm{ClC}_{6} \mathrm{H}_{4} \mathrm{CHO} \\
\text { (p-chlorobenzaldehyde) }\end{array}$ & 69.46 & $7.77 \times 10^{7}$ & 67.38 & 90.79 & 74.19 \\
\hline 2. & $\begin{array}{c}\mathrm{p}-\mathrm{CH}_{3} \mathrm{C}_{6} \mathrm{H}_{4} \mathrm{CHO} \\
\text { (p-methylbenzaldehyde) }\end{array}$ & 57.78 & $1.28 \times 10^{6}$ & 56.16 & 88.00 & 101.24 \\
\hline
\end{tabular}

\section{MeChanisM}

The reacting species $\mathrm{H}_{2} \mathrm{CrO}_{4}$ generated by the hydrolytic equilibrium as:

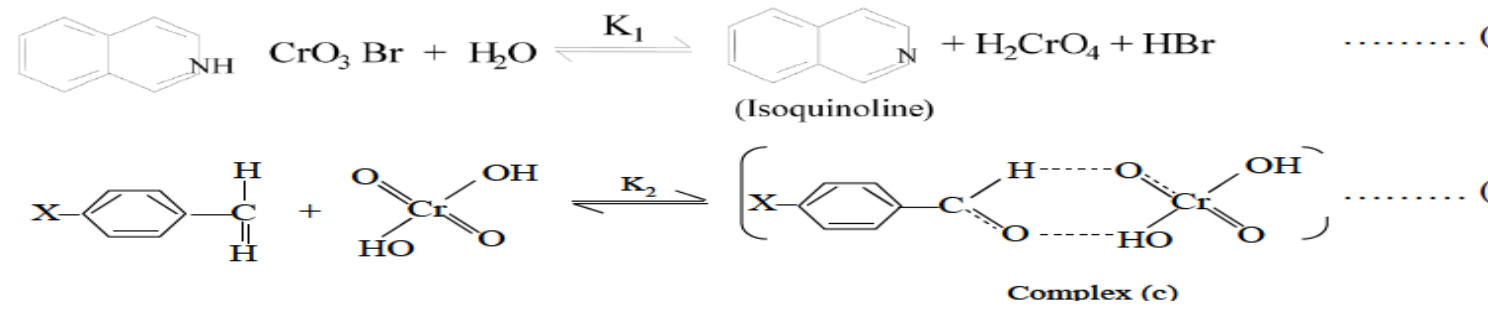

Where, $\mathrm{X}=-\mathrm{Cl}$ and $-\mathrm{CH}_{3}$ for para-chloro benzaldehyde and para-methyl benzaldehyde respectively.

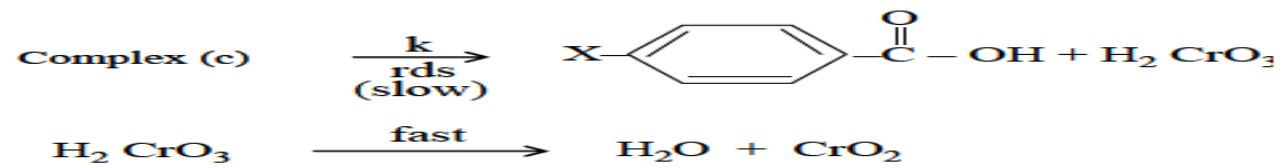

The active species attacks the keto form of substrates to form polar complex in the activated state which in turn decomposed into products.

The rate law according to mechanism can be derive as follows :

Rate $\infty$ [complex]

Rate $=\mathrm{k}[$ complex $]$

and, the final rate law is deduced as:

$$
\text { Rate }=\frac{\mathbf{k} \mathbf{K}_{1} \mathbf{K}_{2}[\mathbf{S}]\left[\mathbf{H}^{+}\right]}{[\mathrm{IQ}] \mathbf{K}_{1}+\mathbf{K}_{2} \mathbf{K}_{1}[\mathbf{S}]}
$$

The corresponding expression (7) becomes as Rate $=\mathrm{k}$ at low concentration of substrate. Further in version of equation 7 results into 8 .

$$
\frac{1}{\mathbf{k}_{\text {obs }}}=\frac{\mathrm{IQ} \mathrm{K}_{1}+\mathrm{K}_{2} \mathrm{~K}_{1}[\mathrm{~S}]}{\mathbf{k} \mathbf{K}_{1} \mathrm{~K}_{2}[\mathrm{~S}]\left[\mathrm{H}^{+}\right]}
$$

Which can also be verified by potting $1 / \mathrm{k}_{\text {obs }}$ against $1 /[\mathrm{S}]$ and such plots for the two substrates, were also found to be linear. The observed order of reactivity was found as:

\section{P- $\mathrm{CH}_{3} \mathrm{C}_{6} \mathrm{H}_{4} \mathrm{CHO}>\mathrm{P}-\mathrm{Cl} \mathrm{C} \mathrm{C}_{6} \mathrm{H}_{4} \mathrm{CHO}$}

The study reveals that p-methyl benzaldehyde exhibits faster rate than P-chlorobenzaldehyde, which may be attributed due to side rection ${ }^{\mathbf{1 2}}$ and existed dominancy of steric and inductive effects prevailing in them are main reasons of above order of reactivity. The thermodynamic parameters are well in accordance to our results shown in Table 3. The reactions are enthalpy controlled. The reactivity and intermediate complex formed can be explained with entropy results. Similar mechanism have also been reported by authors with IQBC. ${ }^{\mathbf{1 3}}$

\section{CONCLUSION}

Electrophilic attack of the $\mathrm{H}_{2} \mathrm{CrO}_{4}$ on the keto form of substrate leads to the formation of intermediate complex in a fast prior equilibrium, which then decomposes in slow steps to yield the products. The 
entropy was negative for the two para-substituted benzaldehydes, indicating the polar nature of transition state lead to immobilization of solvent molecules around the charged ends which results in to the loss of entropy. The existed domanacy of steric and inductive effects among the molecules are the main reasons of said order of reactivity.

\section{REFERENCES}

[1] Patwari, S.B., Khansole, S.V. and Vibhute, Y.B. : J. Iran. Chem. Soc., 2009, 6(2), 399-404

[2] Patwari, S.B., Khansole, S.V. and Vibhute, Y.B. : J. Iran. Chem. Soc., 2009, 6(2), 399-404Patwari, S.B.,

[3] Khansole, S.V. and Vibhute, Y.B. : J. Iran. Chem. Soc., 2009, 6(2), 399-404.

[4] Patwari, S.B., Khansole, S.V. and Vibhute, Y.B., J. Indian Chem. Soc., 2009, 86(12), 1343-1346.

[5] Tiwari, S., Khan, M.U. Tiwari, B.M.L., Tiwari, K.S. and Valechha, N.D., Oxid. Commun., 1999, 22, No.3, 416-423.

[6] Khan, S., Khan, M.U., Singh, S.K., Gupta, H.D., and Singh, P.K., Asian J. Chem., 2007, 15 (2), 5267-5270.

[7] Mohan, K.V., RaghunathaRao, P., and Sundaram, E.V., J. Indian Chem. Soc., 1984, 61, 225.

[8] Krishnamurti, M., SanjeevaReddy, C.H., and Sundarm, E.V., J. Indian Chem. Soc., 1989, 28A, 288.

[9] Radhakrishnamurti, P.S., Rath, N.B. and Pandey, R.K., Indian J. Chem., 1988, 27, 963.

[10] Alhaji, N.M.I., and Sofia, S. Lawrence, Mary, E. J. Chem., 2011, 8(4), 1472, 1477.

[11] Singh, S.K., Gupta, H.D., Khan, M.U., and Baghel, S.K., Orbital Elec. J. Chem. 2018, Vol. 2, No. $2,118$.

[12] Riley, H.L., Moreley, J.F., and Friend, N.A., J. Chem. Soc., 1932, 1875.

[13] Dwivedi, Arun Kumar, Dwivedi, A.P. and Sharma, K.N., J. Adv. Chem., 2019, 16, 6354-6359.

Citation: Arun Kumar Dwivedi, et.al., (2019). "Oxidative of Some Substituted Benzaldehydes by Isoqauinolinium Bromochromate". International Journal of Advanced Research in Chemical Science (IJARCS), 6(4), pp.41-45. DOI: http://dx. doi.org / 10.20431/2349-0403.0604003.

Copyright: () 2019 Authors. This is an open-access article distributed under the terms of the Creative Commons Attribution License, which permits unrestricted use, distribution, and reproduction in any medium, provided the original author and source are credited. 